\title{
Relações exteriores nas políticas indígenas em São Gabriel da \\ Cachoeira: indigenização da prefeitura e incorporação de alteridades
}

\author{
Aline Fonseca lubel \\ Universidade Estadual de Campinas / Campinas, SP, Brasil \\ $\boldsymbol{\nabla}$ alineiubel@gmail.com
}

\section{RESUMO}

À luz de algumas considerações etnográficas sobre o ethos rionegrino de valorização e incorporação da alteridade, este artigo reflete sobre a avaliação feita pelos próprios índios a respeito da "gestão indígena" na prefeitura de São Gabriel da Cachoeira (AM). O argumento é que, sendo a prefeitura um elemento que implica em relações exteriores ao mundo indígena, a tentativa de indigenizá-la exigiria pelo menos dois procedimentos: a incorporação de relações e "elementos de alteridade", e a incorporação de índios na prefeitura. Segundo alguns dos envolvidos nessa experiência, a gestão "não teria sido indígena", pelo excesso de "gente de fora" e por uma certa "contaminação" do prefeito pela "política dos brancos". Pergunta inescapável, no entanto, é referente ao quanto o próprio Estado suportaria uma dinâmica que implica na simultaneidade de diferenças intrínsecas às relações entre índios na região. $A$ análise sugere que, antes de uma suposta incapacidade indígena para a gestão do Estado, há a incapacidade do Estado em lidar com/incorporar diferenças e alteridades. 
Neste artigo busco relacionar as ideias de valorização e incorporação da alteridade e das coisas que vêm de fora, recorrentes em etnografias e na teoria antropológica das terras baixas da América do Sul, com as avaliações da experiência de "gestão indígena" na prefeitura de São Cabriel da Cachoeira, no Alto Rio Negro, entre 2009 e 2012. 'Essas avaliações locais lançam mão do argumento de que, a despeito de prefeito e vice-prefeito serem índios, a gestão não teria sido indígena, justamente pelo excesso de "gente de fora"z nos quadros da prefeitura. O que, antes de qualquer coisa, leva a refletir sobre quais alteridades são consideradas interessantes de serem incorporadas, como se dão essas incorporações e em que momentos e espaços da vida indígena espera-se que ocorram. Além disso, meu argumento segue no sentido de que o pretendido, naquele caso, era a indigenização da prefeitura, processo que implicaria em um duplo movimento: a incorporação da prefeitura no mundo indígena e, num movimento complementar e simétrico, a incorporação de índios na prefeitura, ambos desejos bastante antigos da população indígena local.

Tendo como destino uma reflexão sobre a incapacidade do Estado em incorporar a alteridade e em lidar com a recusa indígena à unificação e com o apreço dos índios pelo múltiplo, passo então à apresentação das expectativas e dos fatos que conduziram à vitória no pleito e à "gestão indígena" na prefeitura de São Gabriel da Cachoeira. Após um breve parêntese teórico sobre a importância do princípio da incorporação de alteridades no mundo ameríndio, apresento os impasses e conflitos que se colocaram na relação entre prefeito e vice-prefeito, e as avaliações feitas da gestão, que exploram as dimensões desejáveis de incorporação de alteridades e de "gente de fora" a partir dos sentidos possíveis e cabíveis ao termo liderança. Um segundo parêntese teórico será feito então, para refletir sobre alguns termos antropológicos para a chefia indígena. Após uma última volta aos dados etnográficos, o último parêntese, a título de conclusão, sugere a possibilidade de uma atualização da ideia clastreana de contra-o-Estado, dado que hoje os próprios índios se interessam por fazer uma política estatal (ainda que reinventada aos moldes indígenas). Um primeiro curto-circuito ou impasse a ser resolvido pelos índios nessa investida contra-o-Estado e com-o-Estado (ou seja, de dentro dele) é a respeito de categorias como o um, o dois e o múltiplo, números adequados ou inadequados de modos diferentes na política indígena e na política estatal, conforme fica sugerido pela etnografia aqui trazida à baila.

\section{POLÍTICA INDÍGENA NO ALTO RIO NEGRO: DO MOVIMENTO À PREFEITURA}

Complexo multiétnico e multilíngue formado por mais de vinte grupos, o Alto Rio Negro localiza-se no Noroeste Amazônico, na fronteira com a Colômbia e a Venezuela, onde só se chega por vias fluviais ou aéreas. ${ }^{3}$ No entanto, a dis-
1 Essa pesquisa contou com o apoio da Fundação de Amparo à Pesquisa do Estado de São Paulo (FAPESP).

2 Opto por utilizar as aspas para os termos e conceitos nativos e o itálico para os mobilizados ou elaborados por mim ao longo da pesquisa, distinguindoos e destacando-os.

3 Trata-se das seguintes famílias linguísticas: arawak (cujas etnias são: Baniwa, Coripaco, Warekena, Tariano [que atualmente adotou o tukano como língua] e Baré [que há muito fala nheengatu]); tukano oriental (Arapaso, Bará, Barasana, Desana, Karapanã, Kubeo, Makuna, Miriti-Tapuya, Piratapuia, Siriano, Tukano, Tuyuka, Kotiria/Wanano); maku (Hup/Hupda, Yuhup, Döw, Nadöb). Além dessas, há os Yanomami, que se situam de maneira transversa ao sistema e por isso sua articulação deve ser tomada com cautela. Como veremos, há um tanto de incertezas sobre "se", "quando", "onde" e "como" tais grupos se constituem enquanto "etnias". Ver nesse sentido o excelente artigo de Andrello (2016). A classificação acima, porém, é uma combinação que encontrei em algumas monografias, bem como no site do ISA (Instituto Socioambiental: http://www. socioambiental.org/, acessado em 04/03/2016). Nessa perspectiva, diferentemente do que costuma ocorrer em outros contextos etnográficos, não usaremos aqui o termo "povo", mas sim "etnia" para tratar desses diferentes 
tância em relação a grandes cidades brasileiras e a dificuldade de acesso não fizeram com que a região permanecesse isolada. Habitantes originários, os índios lá vivem desde os tempos pré-colonização narrados na mitologia regional. Os brancos, por sua vez, circulam por lá desde os tempos coloniais, tendo se estabelecido de modo mais efetivo a partir do século $17 .{ }^{4}$ Quando chegaram, porém, "já eram conhecidos dos índios, pois figuravam nos mitos". São muitas as passagens que relatam o surgimento e as façanhas desses seres - os brancosgeralmente tidos como impulsivos, incontinentes, desmedidos e portadores de outras características geralmente atribuídas a gente hierarquicamente inferior (Lasmar, 2005; Andrello, 2006; Hugh-Jones, 1988 e 1992; Nascimento, 2017). Fato é que todas essas narrativas marcam claramente a diferença profunda entre índios e brancos. Trata-se de duas gentes diferentes, dois mundos heterogêneos. Na história, tempo pós-mítico, as diferenças entre eles se recolocam em outros termos. Além disso, as diferenças entre os próprios índios e entre tipos de brancos são atualizadas e transformadas constantemente. Não cabe neste artigo fazer uma arqueologia das relações entre índios e brancos desde que o primeiro colonizador chegou ao Alto Rio Negro, há mais de trezentos anos, ainda que isso seja pular uma parte importante dessa história. Sem desconsiderar que o que ocorreu em tempos recentes e vem ocorrendo no cenário político do município pode também estar relacionado a fatos históricos mais remotos ou ao tempo mítico, gostaria de enfatizar aqui apenas alguns dos lugares e tempos em que se dão os encontros entre diferentes políticas, dos brancos e dos índios; nominalmente, o movimento indígena e a prefeitura.

Certa vez, remontando ao início do movimento indígena no rio Negro, um líder, já falecido, me contou que a primeira associação foi criada no distrito de Pari-Cachoeira, no ano de 1972, por inspiração e com recursos dos missionários salesianos. ${ }^{5}$ Chamava-se União Familiar Animadora Cristã (UFAC), "porque os padres só davam nomes assim, ligados à espiritualidade, nome de santo, de uma expressão espiritual”. Esse líder, na ocasião, acrescentou que a organização em associações "nunca foi iniciativa dos índios e nunca será. Não era uma coisa nossa. Mas, querendo ou não, o índio sempre vai se envolver naquilo que nãoé dele". Os primeiros incentivos podem ter vindo da Igreja, é verdade. Mas os índios poderiam ter recusado este modo de organização. Ao contrário, o que a história posterior aos anos 1970 nos mostra é que eles não somente aderiram a esta lógica, como fizeram proliferar as associações em quantidade e qualidade. Evidentemente, não sem transformá-la e reinventá-la criativamente. Os trechos destacados na fala desse líder dão a entender que são os próprios índios que afirmam incorporar alteridades.

O Alto Rio Negro é reconhecido no cenário nacional pela força e consolidação de seu movimento indígena. Após essas primeiras associações, que tinham caráter cooperativo ou a função de organizar as atividades coletivas de uma grupos ou coletivos que se relacionam no Alto Rio Negro, sobretudo porque é o termo mais utilizado localmente pelos próprios índios.

4 O segundo capítulo do livro de Geraldo Andrello (2006) fornece um excelente apanhado da história da colonização do Rio Negro.

5 Missões salesianas começaram a ser implantadas por todo o Alto Rio Negro a partir de 1914. As atividades missionárias consistiam, dentre outras coisas, na educação escolar das crianças, que era realizada em regime de internato. O principal objetivo das missões era, evidentemente, a conversão dos índios ao catolicismo e, para isso, pensava-se na educação como o meio mais eficaz. Com a implantação de grandes colégios internos em alguns distritos de São Gabriel da Cachoeira, bem como na própria sede do município, boa parte das crianças da geração que hoje tem entre 40 e 60 anos foi afastada do convívio com as gerações mais velhas, o que implicou no enfraquecimento de algumas tradições e de algumas línguas indígenas, mas não no desaparecimento das mesmas. Os internatos começaram a ser fechados na década de 1970, com o aumento da presença militar e estatal na região. Vários dos antigos colégios religiosos são atualmente mantidos pelos governos estaduais e municipais, embora os religiosos ainda tenham bastante ingerência sobre os mesmos. Além disso, tem crescido o número de escolas indígenas na região. 
comunidade, foram criadas inúmeras outras, espalhadas por toda a região, voltadas a lutas em torno dos mais variados temas, como território, saúde, educação, economia, cultura, agricultura, cidadania, direitos políticos, etc. ${ }^{6}$ Pelo menos duas coisas foram importantes nesse momento: os índios cindiram no tocante a diferentes concepções a respeito de lutas como a demarcação de terras, o que promoveu o surgimento de ainda mais associações, e passaram a ter de lidar com diversas exigências legais, como o registro de estatutos e associações em cartório, para que tais associações pudessem firmar convênios e acessar recursos. A esses dois fatos sobrepõem-se outros dois: muitas das divisões que se efetivaram no campo associativo refletiam outras divisões locais (entre famílias, línguas, clãs, locais de residência, etc.); e ter de lidar com as diversas exigências legais fez surgir especialistas em burocracia escolarizados, falantes de português e, mais recentemente, capacitados no uso de computadores, mas não necessariamente localizados nos estatutos superiores das hierarquias locais. ${ }^{7}$ Ou seja, paralelas às estruturas locais de organização política - muitas vezes baseadas na hierarquia dos clãs, da ordem de nascimento, em relações decorrentes de trocas comerciais ou matrimoniais, em relações interétnicas, etc. - foram instauradas novas estruturas de organização política, prerrogativas, habilidades e capacidades fortemente voltadas a relações exteriores, que promoveram novas distinções internas.

É claro que política, mesmo aquela que pode, por contraste, ser descrita como "tradicional", é voltada (também) para relações com algum tipo de exterioridade - entre malocas, comunidades, grupos familiares, linguísticos ou étnicos. O que gostaria de salientar, no entanto, é que essa nova política, praticada no âmbito do movimento indígena, implicou e implica em duas transformações fundamentais. Primeiramente, ela é em grande parte direcionada a negociações com o governo (brasileiro e estadual) e com outras instituições totalmente externas ao Alto Rio Negro, como igrejas, ONGs, empresas mineradoras, projetos extrativistas, comerciantes brancos, etc. Além disso, ela implica na negociação de inúmeras diferenças internas. Não digo que houve sublimação ou omissão dessas diferenças, ao contrário, o que se vê muitas vezes é o acirramento de algumas delas. Trata-se do fato de que no movimento indígena do Alto Rio Negro algumas diferenças tiveram que ser deixadas de lado em prol de uma articulação pan ou multiétnica e de pautas e reivindicações que diziam respeito a todas as etnias regionais. Este processo de negociação entre diferenças para a constituição de algo chamado movimento indígena do Alto Rio Negro é permanente. Exemplo disso são as constantes alterações nos modos de organização/divisão da área, no estatuto e nas formas de escolha dos líderes na Federação das Organizações Indígenas do Rio Negro (Foirn). Enquanto no tempo das missões a divisão entre os grandes distritos (lauaretê, Pari-Cachoeira, Taracuá) se sobres-
6 A Federação das Organizações Indígenas do Rio Negro (Foirn) é uma associação civil sem fins lucrativos, sem vinculação partidária ou religiosa, fundada em abril de 1987. Atualmente, é composta por cinco coordenadorias regionais e reúne mais de 89 organizações de base representantes das comunidades distribuídas ao longo dos principais rios formadores da bacia do Rio Negro. Para saber mais sobre a fundação da Foirn, o crescimento do número de associações e a consolidação do movimento indígena na região, ver a dissertação de mestrado de Renato Martelli Soares (2012), além do próprio site da Federação: www.foirn. org.br. Sobre o movimento indígena no Alto Rio Negro ver também: Sidnei Clemente Peres (2003), Luiza Garnelo (2002 e 2004) e Gersem José dos Santos Luciano (2006).

7 Crosso modo, pode-se dizer que o principal elemento localizador do mapa social é aquele que se estabelece entre as posições "irmão maior"/"irmão menor"-que, ainda, subordina outras posições como "tio", "avô", "sobrinho", "neto" (Jackson 1983; Chernela 1993). Esse sistema ainda se projeta tanto para as gerações "ascendentes" quanto para as "descendentes", tornando o Rio Negro um caso extraordinário em termos de ancestralidade. Observa-se que, neste cenário, a partir de um determinado ponto (diria que usualmente a $\mathrm{C}+/-3$ ), a patrilinearidade parece se dobrar à terminologia de "irmãos", o que ao mesmo tempo inflexiona a ancestralidade em direção à hierarquia de sibs e dá margem 
saia, hoje, no tempo do movimento indígena, a divisão se dá pelas calhas de rios. Mas, essa divisão atual é fruto de muito debate e reflexão, não foi imposta ou promovida por alguma instituição externa.

Aqui a coisa começa a se complexificar. Se, por um lado, as formas atuais de organização (em associações com estatuto, registros financeiros, organogramas complexos, federação), as capacidades e habilidades nelas envolvidas têm origens ou inspirações em instituições externas ao mundo indígena (igreja, Estado, sindicatos, movimentos sociais de outras categorias), por outro, são reinventadas a partir dos conteúdos internos que sempre organizavam e continuam organizando as diferentes políticas locais e regionais. Ou seja, as relações entre interior e exterior são transformadas e passam, em grande medida, a ser mediadas por novas instituições e pessoas surgidas em um novo momento da história do Alto Rio Negro. Por ora, deixemos os termos interior e exterior assim, sem maiores problematizações, mas voltaremos a eles em momento oportuno ainda neste artigo. Apenas não deixemos de evocar que este conjunto de reflexões, desde aquela na fala do líder indígena citada logo acima, toma o pensamento indígena como movido também pela exterioridade. Não deixa de ser sintomático que a exterioridade da política estatal passa paulatinamente a ser vista também como "negócio de índio" (nos termos do líder indígena), guardadas as devidas proporções. Mas uma digressão provocada por esta breve reflexão nativa poderá revelar que há certa ambiguidade pautando os limites entre o que é interior e exterior, entre querer e não querer participar do que "não é indígena".

Como apontei anteriormente, o movimento indígena no Alto Rio Negro tem lutado e debatido, desde os anos 1970, em torno de variados temas e demandas. Um deles tem sido direitos civis e políticos e política partidária, expresso localmente no "desejo de ocupar o Estado", em "ter vereadores, prefeito e vice-prefeito indígenas" e se posicionar frente a e dentro de um Estado visto como "inimigo", "algoz" e predominantemente "ocupado por brancos". É nesse sentido que certa vez uma liderança indígena me colocou as seguintes reflexões: "quem são os eleitores que durante mais de cem anos elegeram sucessivamente brancos para os cargos mais importantes do município?" e "percebemos que o Estado é um inimigo contra o qual a estratégia de combate é menos eficaz do que a aproximação". Para debater questões como essas, os direitos civis e político-eleitorais dos índios e definir nomes de possíveis candidatos, foram criados nos anos 1990 e 2000 dois grupos, paralelos ao movimento indígena: a Comissão Indígena Suprapartidária (CISP) e o Fórum de Debates de Direitos Indígenas (FDDI). Além desses grupos, um grande número de índios, principalmente aqueles envolvidos no movimento indígena, passou a participar dos partidos políticos (o que não representa um sinônimo de filiação ou fidelidade partidária). ${ }^{9}$ As negociações e consensos a respeito de nomes indígenas candidatáveis demoraram a acontecer, para controvérsias sobre precedências e pertencimentos a determinadas "linhas". Ver também Leirner (2015)

8 Trata-se aqui de um uso local da noção de "tradição", que basicamente é contrastante ao modo de vida contemporâneo, na cidade, em meio a instituições não-indígenas.
9 Para saber mais sobre essas instâncias ver lubel (2015). 
apesar do sentimento comum que era expresso nos termos de "desejo de ocupar o Estado". Somente nas eleições municipais de 2008 chegou-se a uma aliança entre dois indígenas que se candidataram aos cargos de prefeito e vice-prefeito do município. ${ }^{10}$ Eram eles Pedro Carcia (Tariano, do Partido dos Trabalhadores) e André Baniwa (do Partido Verde). $\cdot{ }^{11}$ A ideia de uma chapa indígena multiétnica já havia sido aventada em pleitos anteriores, mas não tinha sido levada a cabo, principalmente devido a querelas partidárias. A aliança entre etnias parecia mais fácil de ser realizada, já que há tempos vinha sendo ensaiada no movimento indígena, o qual, muitas vezes, inclusive, me foi descrito como espécie de "laboratório para a política partidária". No entanto, "todos sabiam" que a aliança entre Pedro e André tinha sido feita para ganhar a eleição, e que, se ganhassem, para governar, tal aliança "precisaria ser refeita".

Para entender as avaliações locais que foram feitas durante e depois da gestão de Pedro e André na prefeitura é preciso considerar pelos menos duas coisas: primeiro, as expectativas em relação ao que seria uma gestão municipal indígena e; segundo, o fato de a aliança selada entre os candidatos na campanha não ter sido preservada. Pelo contrário, a relação entre ambos tornou-se muito tensa logo após a vitória. Expondo de modo breve, as expectativas referentes à "gestão indígena" estavam espalhadas de modo diferenciado entre o movimento, a população, os partidos envolvidos e entre os candidatos eleitos. O movimento indígena acreditava ser "uma oportunidade única de fazer uma administração pública diferente". A esse desejo somavam-se os anseios de André, relacionados à "necessidade de eleger um candidato que entenda nossa linguagem, pensamentos, realidades, necessidades, projetos e programas que possam melhorar as vidas nas nossas comunidades". Além disso, ele entendia que "a gestão não deveria dar as costas ao movimento indígena" e que "o movimento deveria atuar apoiando a prefeitura". De sua parte, a população esperava (como espera a cada pleito) que se estabelecesse uma "nova relação do governo municipal", "maior atenção às comunidades e aos indígenas da região" e "mudanças concretas no modo de administrar e governar", no sentido de mais transparência e compartilhamento de tomada de decisões. No entanto, alguns partidos esperavam cargos, secretarias municipais e, eventualmente, a quitação de algumas dívidas (econômicas e políticas) contraídas durante a campanha. Foi aqui que, aparentemente, Pedro se viu um tanto imobilizado localmente e obrigado a trazer de fora (Manaus e outras cidades) profissionais que passaram a ocupar postos importantes dentro da administração municipal.

Ao argumento que desenvolvo aqui importam mais as expectativas do movimento indígena, pois nelas encontramos os significados do que seria uma "gestão indígena" da prefeitura. Nos termos de alguns líderes, essa gestão deveria "incluir mais índios do que brancos", "ter um prefeito e um vice que continu-
10 O município já tinha contado com um vice-prefeito indígena, eleito em 1996. Este, no entanto, faleceu poucos meses depois de assumir seu cargo na prefeitura.

11 Não faz sentido omitir ou alterar os nomes desses dois personagens, pois são figuras públicas e conhecidas na cidade e fora dela. $O$ nome de outros líderes e pessoas que participaram desta pesquisa foram, no entanto, omitidos, sobretudo porque este recurso não prejudica os argumentos aqui desenvolvidos. 
assem agindo e pensando como índios, que não se deixassem contaminar por lógicas externas ou brancas". Ou seja, havia de antemão uma medida de cálculo complexo entre o quanto deveria ser incorporado do exterior (de lógicas e pessoas) e do quanto dever-se-ia manter de características da política indígena (feita no movimento e pelos líderes indígenas). Havia também uma diferença sutil, mas evidente, entre incorporação e contaminação. No plano dos anseios, os índios deveriam continuar incorporando conhecimentos, ferramentas e técnicas que já vinham sendo incorporadas (e transformadas) nos processos de escolarização e no movimento indígena - falo aqui das capacidades de escrita e leitura; de gerir recursos; da compreensão e redação de editais, projetos e prestações de contas; do entendimento do funcionamento de órgãos públicos; tudo isso atravessado ou tangenciado pelas capacidades em ferramentas de informática, administrativas, contábeis, etc. $\mathrm{O}$ auxílio de alguns brancos até poderia ser necessário ou desejável, do ponto de vista indígena, mas tais incorporações não deveriam implicar, jamais, na transformação de índios em brancos. Transformação que, mais uma vez do ponto de vista indígena, é impensável e vem sendo politicamente rebatida pelo movimento indígena. Neste sentido, incorporação era pensada como diferente de contaminação.

\section{RELAÇÕES ENTRE "COISAS DIFERENTES": DA ETNOLOGIA NAS TERRAS BAIXAS SUL-AMERICANAS ÀS POLÍTICAS RIONEGRINAS}

A questão da relação com a alteridade nas terras baixas sul-americanas está intimamente ligada ao debate sobre sistemas e terminologias de parentesco e à centralidade que o problema da afinidade ocupa neste. Viveiros de Castro resume assim o início desta discussão:

A caracterização de terminologias sul-americanas como "dravidianas" começa, salvo engano, com Maybury-Lewis (1967), depois com Basso $(1970,1975) e$ finalmente com Overing Kaplan (1972, 1973, 1975). Mas é Rivière (1969) quem aproxima efetivamente os contextos sul-americanos e indiano, e quem mais tarde (1976) vai sugerir que a aliança simétrica expressa nas terminologias dravidianasé um invariante amazônico. (1993: 150)

Aproximando-se do material rionegrino (mas também dos ]ê e BororoMaybury-Lewis-e dos Panare-J-P Dumont), a partir do trabalho de Stephen Hugh-Jones, Overing Kaplan (1981) argumenta que os Barasana têm a vida social e o universo concebidos como fundamentados na relação entre "coisas diferentes". O protótipo da relação é aquela entre afins, constantemente tensa, sujeita a riscos e potencialmente perigosa. Mas, para além deste protótipo, os 
princípios metafísicos de elaboração da diferença são dados pelo conjunto de relações de troca com o outro. Essa é a tal "estrutura elementar de reciprocidade", construída pelas trocas que permitem a autoperpetuação, não necessariamente de grupos, mas de formas de relacionamento (Overing Kaplan, 1983: 346).

Entrando neste debate, Viveiros de Castro desenvolve seu argumento fundamentalmente em três frentes: 1) a despeito da multiplicidade e diversidade de situações etnográficas, deve-se manter a estrutura da aliança simétrica, baseada em uma terminologia "de tipo dravidiana" típica (Dumont, [1953] 1975), como base teórica mínima; 2) ao caráter diádico e simétrico da estrutura terminológica dravidiana, deve-se sobrepor o plano da relação entre o próximo e o distante, hierárquica, fundamentada em uma lógica classificatória mais ampla, que se coloca no triadismo "consanguíneos/afins/inimigos" e circunscreve o âmbito do parentesco stricto sensu; 3) portanto, o parentesco não deve ser considerado causa suficiente para o estudo dessas sociedades. Cabalzar diz que:
A relação, densa em significados, entre o próximo e o distante, o interior e o exterior, envolve mais que o predomínio de uma lógica da consanguinização, no sentido de cognação, na primeira esfera, e da afinização, na segunda. Existem também os inimigos, que estão além dos afins, levando ao extremo as conotações que lhes são próprias. (2009: 112)

Nos termos de Viveiros de Castro, "é o parentesco como um todo que se vê primeiro englobado pela afinidade, finalmente subordinado à relação com o exterior" (1993 apud Cabalzar, 2009). Ou seja, seria a relação com o exterior que englobaria todas as outras, inclusive a prototípica relação entre afins. Mas, conforme sugerido aqui e voltando à relação interior/exterior, é preciso esclarecer que Viveiros de Castro nos abre a perspectiva sobre isso ao se perguntar em relação a quê são constituídos os coletivos indígenas. A partir da linguagem do dado e do construído sua resposta inicial foi a de que tais coletivos se constituem pela alteridade (pelo exterior, portanto), mas, que esse exterior é imanente ao próprio interior. Nessa esteira, Andrello explica que

dizer que uma sociedade não tem interior não significa dizer meramente que sua existência depende do que está fora dela, mas que este fora, a alteridade, é uma relação interna a ela. Oexterior está, por assim dizer, dentro, à medida mesmo que um interior vem a ser (2006: 412).

Portanto, não é menor trazer este debate sobre as relações entre interior e exterior, e entre "coisas diferentes"/alteridades, para o atual contexto das políticas indígenas e suas interfaces com o Estado. No Alto Rio Negro o Estado é associa- 
do à figura do branco. Então, é nos termos dessa polarização que cabe pensar as relações índios/brancos, índios/Estado, interior/exterior. Nesse sentido, a questão de Geraldo Andrello sobre "se teriam os brancos ocupado a posição de afim potencial no Uaupés" (2006: 409), nos oferece um ponto de partida interessante. Ainda que o autor faça tal reflexão a partir da análise do mito de origem Tukano, ela despontou no contexto de uma indagação mais geral sobre o significado da noção de civilização do ponto de vista indígena. Assim suas considerações são interessantes também para o caso etnográfico aqui apresentado.

Primeiramente, argumenta Andrello, é por intermédio da incorporação de potências exteriores que se alcança a reprodução social interna dos grupos rionegrinos. Nesse sentido, "o branco ocuparia, tanto quanto o inimigo, a posição de um afim potencial" (2006: 409), sendo fonte de itens simbólicos e materiais (e não de cônjuges). Em seguida, o autor acrescenta a esse esquema rionegrino de posicionamento dos grupos indígenas e dos brancos as considerações feitas por Viveiros de Castro, escrevendo que:

(...) o mundo dos brancosé, assim, o exterior do mundo dos índios. Trata-se, porém, de um exterior imediatamente interior, pois é abordado no mito por um processo de disjunção e conjunção espaço-temporal, isto é, pela apropriação por parte dos brancos daquelas mercadorias que depois trariam novamente ao Uaupés (Andrello, 2006: 422).

A narrativa mítica e histórica mobilizada por Andrello indica que depois que chegaram ao Rio Negro, os índios começaram a descer para ver os brancos e se apropriar de suas coisas, suas potências. Assim, o autor confirma que o branco pode ser alocado na categoria de um afim potencial, detentor de poderes que cumpre apropriar, o que poderia ser feito por intermédio das mercadorias, pois estas "se insinuaram como objetificações de capacidades subjetivas" (Andrello, 2006: 422). Hoje é possível acrescentar a esses poderes apropriáveis as políticas dos brancos/estatais, uma capacidade há muito monopolizada pelos brancos, mas perfeitamente incorporável e transformável pelo mundo indígena.

\section{LIDERANÇA INDÍGENA: SER OU NÃO SER NEM SEMPRE É UMA QUESTÃo}

Feito esse primeiro parêntese teórico, voltemos à etnografia. Tão logo a vitória nas urnas foi declarada, parte daquelas expectativas tiveram que ser trazidas para o plano da realidade imposta pelo encontro entre os diferentes mundos da política estatal e da política indígena. Para complicar ainda mais, este encontro deu-se entre dois indígenas - Pedro Carcia e André Baniwa - e não entre índios e brancos. Quanto a isso, a diferença de opinião a respeito da ideia de liderança 
que se desenhou entre Pedro e André deu o tom das impossibilidades da aliança se reconfigurar para que ambos governassem juntos.

Durante a gestão de Pedro e André, este escreveu um artigo, o qual intitulou "O que é ser liderança segundo Mitologia, Ciência e Religião?". O mote para a reflexão, apresentado na epígrafe, é a seguinte fala que Pedro teria dirigido a André:

Você não é mais liderança indígena, você nãoé mais da comunidade indígena, hoje vocêe é vice-prefeito! Eu não sou mais liderança indígena, não sou mais da comunidade indígena, hoje eu sou prefeito. Prefeito e Vice-Prefeito não têm nada a ver com liderança mais.

Isso teria sido dito pelo prefeito após ele ter definido André como "consultor externo" na prefeitura, assim que este apresentou um relatório sobre a gestão numa reunião do Conselho Diretor da Foirn ${ }^{12}$. É preciso notar que a experiência de indígenas da região em diversos cargos e órgãos da administração pública vem de longa data. Desde os anos 1980 há índios que assumiram cargos na Funai, na prefeitura, em secretarias municipais e estaduais, em ministérios federais, para dar apenas alguns exemplos. Sempre que possível o movimento tenta gerenciar ou, ao menos, influenciar de algum modo quem são essas pessoas e suas atuações. Além disso, é muito comum que elas sejam chamadas a prestarem contas, apresentarem relatórios e serem avaliados em reuniões do movimento indígena. Assim, um convite da Foirn a prefeito e vice-prefeito indígenas para relatarem a experiência na gestão era mais do que esperado. As reações de André e Pedro, no entanto, foram diferentes.

Desde o início da gestão Pedro se afastou do movimento indígena e também de seus correligionários municipais do PT, na medida em que se aproximou de uma parcela do diretório estadual do partido. Isso me foi relatado não apenas por André, mas também por outros líderes. A explicação à qual André chegou em relação àquele primeiro distanciamento de Pedro em relação ao movimento está relacionada à ideia de liderança. Do ponto de vista de André,

liderança é uma essência ou valor importante de uma pessoa que a exerce, a qual, dependendo do momento pode receber títulos temporários como capitão da comunidade, presidente do bairro, da associação, da cooperativa ou do Brasil.

Mas essas pessoas "nunca deixarão de ser lideranças independente de terem títulos ou não". Ou seja, uma vez que se tenha atuado como liderança indígena, é impossível deixar de sê-lo, pois para que isso pudesse acontecer, tal pessoa foi "preparada", "escolhida", "designada", agregando à sua pessoa "capacidades", "prerrogativas", "essências" e "valores" que dela não são facilmente extraíveis"

12 A Federação das Organizações Indígenas do Rio Negro conta com diversas instâncias em seu organograma. Entre elas consta o Conselho Diretor, composto por cinco representantes (entre eles o Presidente) das cinco coordenadorias regionais que abrangem a totalidade da região. Tal Conselho se reúne pelo menos uma vez por ano.

13 A não ser por feitiço ou decisão coletiva, como relatado por Clastres em O infortúnio doguerreiro selvagem (2004). 
Ficam desenhadas as divergências entre as opiniões de Pedro e André a respeito do que seria a liderança indígena.

Há ainda um apontamento feito por André em seu artigo. Segundo ele, na narrativa baniwa há dois tipos diferentes de mundo: um composto por "gente como nós, em baniwa chamamos de walimanai" e outro composto por "árvores, animais e outros seres, mas que também são gentes como nós, que possuem seus espíritos e poderes". Os "conquistadores do direito walimanai na história da criação baniwa foram três: Ñapirikoli, Dzooli e Eeri”. Assim segue André em seu artigo:

O primeiro sempre descobria ou desconfiava o que vinh a acontecer de ruim ou de coisa boa. Para a segunda pessoa perguntava sempre: o que vamos fazer? E respondia com uma proposta. Para a terceira pessoa perguntava o que achava. Esta confirmava concordando com a proposta do segundo ou não. Foram três lideranças com espírito de trabalho em equipe constantemente que conquistaram o direito que temos hoje como humanidade walimanai. (André Baniwa, 2010)

\section{ALGUNS TERMOS PARA A CHEFIA INDÍGENA}

Isso abre uma brecha para pensar algumas proposições antropológicas colocadas por diferentes autores a respeito da chefia indígena, em particular a ameríndia. Em quase todas elas, assim como na fala de André, a questão da liderança/ chefia está relacionada a vários tipos de negociação: com a coletividade, entre líderes e com alguma esfera exterior. De outro modo, a chefia ameríndia tem como designação a manutenção da boa relação entre interior e exterior. ${ }^{14}$ Patrick Menget, relembrando Clastres, escreve que este autor apela à noção de política (politie), sem, no entanto, precisar os limites e as condições de permanência:

La politie, c'est pour une société donnée le cadre nécessaire à la distinction entre un intérieur et un extérieur. Le maitien de cette distinction exige l'application de moyens assurant un degré satisfaisant de sécurité vis-à-vis de l'extérieur et de concorde à l'intérieur. (...) l'existence de la politie est, elle, réputée universelle (1993: 60-1)..$^{15}$

Menget está dialogando com Clastres a partir do caso etnográfico da chefia xinguana, onde os chefes são titulares, no sentido de que herdam este título de sua linhagem. Mas, além disso, associam-se a esse título uma competência especial no domínio linguístico, uma proeminência no domínio das relações entre comunidades e um certo número de qualidades pessoais. Essas competências tornam-se visíveis, sobretudo, em cerimônias e rituais. Assim, Menget chega à

\footnotetext{
14 Nesse sentido, pode-se indagar sobre os sentidos de Pedro ter colocado André na condição de "consultor externo". Se externo à prefeitura, ele é colocado justamente na posição de liderança indígena, o que vai no sentido contrário à afirmação feita por ele de que André não era mais liderança indígena. Mas, ele foi colocado também como externo à prefeitura. Em que posição, então, Pedro localizou André?

15 A politie, é para uma determinada sociedade o quadro necessário à distinção entre um interior e um exterior. A manutenção desta distinção exige a aplicação dos meios que assegurem um grau satisfatório de segurança em relação ao exterior e em concordância com o interior. (...) a existência da politie é considerada universal. (tradução minha)
} 
formulação de que o poder político (de um chefe) está relacionado à capacidade de fazer fazer. Isso se coaduna à colocação de Perrone-Moisés, de que um chefe ameríndio "é aquele que inicia um movimento, movimento este que simultaneamente constitui o grupo e o constitui como chefe" (2011: 875). À luz da ideia clastreana de "chefia sem poder", muitos pesquisadores demonstraram etnograficamente sutilezas locais desse princípio. Como sugestão geral, acaba permanecendo a ideia de que um chefe ameríndio só existe em função da coletividade que o constitui. Se ele deixa a desejar em suas funções ou se ultrapassa limites do que dele é esperado, a coletividade tende a obstruir sua condição de chefe.

É claro que tudo isso tende a se complexificar na medida em que se estreitam as relações dos indígenas com o Estado brasileiro, sobretudo após a Constituição de 1988. Quando, reconhecidos como sujeitos de direitos, os indígenas acessam novas fontes de prestígio e formas de autoridade. Perrone-Moisés afirma que:

São professores, agentes de saúde, funcionários, geralmente jovens adultos, que muitas vezes constituem "lideranças" em oposição aos velhos "chefes sem poder" de quem falavam Lowie e Clastres. São também múltiplas organizações indígenas, cujas constituição e operação colocam outras tantas questões. Como as confederações registradas nas fontes históricas, novas formações e movimentos políticos ameríndios não podem ser compreendidos senão a partir de sua própria filosofia política. (2011: 876-7)

Reside aqui um contraste entre as políticas indígena e estatal, no qual opera uma espécie de curto-circuito quando as posições num e noutro espaço se sobrepõem. O caso etnográfico da prefeitura de São Cabriel da Cachoeira sugere que quando duas lideranças indígenas foram eleitas houve deslocamentos tanto da condição de liderança indígena quanto da condição de político estatal, sobretudo no que diz respeito aos modos de relacionamento com alteridade/ exterior e com a coletividade que são esperados na política estatal e na política indígena. Esse contraste mostra que a política na prefeitura feita por um índio contém uma espécie de contradição. Poderíamos falar em contradição nos termos wagnerianos. Lembremos que Pierre Clastres $(2003,2004)$, mas também Roy Wagner, argumenta que o chefe ameríndio (ou tribal, para o segundo autor) é uma pessoa a quem cabe a tarefa de coletivizar. Segundo Wagner:

o indivíduo que deseja aprender a compelire controlar esse poder sobre o coletivo - o chefe, o sacerdote, o especialista ritual, o monge, o curador ou o xamã - precisa aprender a 'fazer' os a tos coletivizantes pelos quais esse poder é precipitado sem invocar a inconveniência da vergonha ou o terror paralisante da possessão ou viti- 
mização por esses poderes. ${ }^{16}$ Ele precisa aprender uma inversão da ação convencional, transferindo a seriedade que ordinariamente se concede ao convencional e ao moral para as demandas de seu 'poder', mas sem transparecer que está fazendo isso. Ele precisa levar as tendências de sua histeria 'até o fim', a ponto de ser o seu poder (de atingir uma conexão completa ou união com ele), mas precisa também esforçar-se para manter a imagem de humanidade. Pois o problema aqui não é o de perder contato efetivo e desaparecer em um mundo próprio; é antes o de perder a própria motivação moral. (ênfase minha, Wagner, 2010: 160)

É nesse sentido que Wagner chama essas figuras - chefe africano ou xamã siberiano, por exemplo-de "fazedores de coletivo". ${ }^{17}$ No entanto, essa tarefa lhe exige aprender a viver uma ordem de motivações e experiência invertida,

fazendo o que os outros consideram inato e ao mesmo tempo mantendo suas relações sociais e morais com eles. Em suma, ele é obrigado, à maneira de seus congêneres ocidentais, a continuamente enganar os outros do mesmo modo que estes, sem o saber, aprenderam a enganar a si mesmos - a viver uma vida de obviação que é o caminho para a iluminação. (idem, ibidem)

Vemos que há aqui a ideia de que esta posição, de chefe, exige uma inversão. Assim, pode-se ler a proposição wagneriana de que um chefe é o seu poder como em algo semelhante (ou complementar) àquela clastreana do chefe sem poder.

Clastres se pergunta o que faz um chefe sem poder. E sua resposta é:

Essencialmente, compete-Ihe assumir a vontade da sociedade, de mostrar-se como uma totalidade una, isto é, assumir o esforço concertado, deliberado, da comunidade, com vistas a afirmar sua especificidade, sua autonomia, sua independência em relação às ou tras comunidades. (Clastres, 2004:147)

Ou seja, ao seguir essa lógica, a indigenizaçao da prefeitura suporia que a prefeitura fosse autônoma (o que não implica em descartar a incorporação de elementos exteriores) e independente em relação às outras comunidades (e neste caso, as outras comunidades seriam os brancos).

No entanto, argumento que um chefe indígena na prefeitura acrescentaria a esse esquema, além da inversão, uma contradição. Nos termos do próprio Wagner, poderíamos falar em "contradição dialética". Exemplos de contradições dialéticas dados pelo autor são bispos e papas que têm amantes e famílias, executivos e políticos maquinando para "fazer as coisas parecerem corretas", cientistas que "trapaceiam" em suas metodologias. Segundo o autor, esse é um modo de ação cultural que usa a dialética em lugar de incorporá-la, "se bem que
16 Isso é o que André Baniwa também fala a respeito do que seria liderança, em seu artigo: "liderança é aquele que trabalha pelo coletivo, age pelo coletivo sempre ouvindo primeiro os seus representados" e "Liderança é aquele que representa um grupo, povo ou a sociedade segundo seus objetivos que pode ser escolhido ou não. É aquele que fala por coletivo depois de ouvir, ver, analisar a situação que queiram resolver para melhorar. Daí vem a determinação natural de ser liderança local, regional ou nacional." Ele acrescenta que "Liderança é uma essência ou valor importante de uma pessoa que a exerce" e, nesse sentido, é permanente. Ou seja, não existe ex-liderança. O que há são títulos temporários-capitão de comunidade, vereador, prefeito, presidente de associação, etc.

17 Ver também Gauchet (1980) e Adler (1980). 
ao usá-la seja por sua vez usado por ela, transformando esforço cultural em um desenvolvimento automotivador" (Wagner, 2010: 194). É preciso esclarecer que o autor entende por dialética a tensão ou alternância entre duas concepções ou pontos de vista simultaneamente contraditórios e solidários entre si (neste sentido, é quase o que Lévi-Strauss chama de "oposições", o que é salientado pelo próprio Wagner). E mais, invenção e convenção mantêm entre si uma relação dialética, qual seja, ao mesmo tempo de interdependência e contradição.

\section{... DE VOLTA À ETNOGRAFIA}

A etnografia da prefeitura indígena de São Cabriel da Cachoeira apresenta um caso em que se acrescenta contradição (dialética) à invenção, para dizer em termos wagnerianos. Ou seja, não há, de antemão, nenhum tipo de impossibilidade ou incompatibilidade entre índios e prefeitura, entre política indígena e política estatal. Se pensarmos com Wagner, a relação dialética entre invenção e convenção (que é ao mesmo tempo de interdependência e contradição) é, justamente, constitutiva, seja nas "tradições diferenciantes" (tribais, camponesas e étnicas) seja nas "convencionalizantes". Dentre outras coisas, é o modo como invenção e convenção se relacionam dialeticamente que distinguem esses diferentes modos de constituir grupo, humanidade ou sociedade.

Particularmente interessante é que este caso etnográfico trata de uma relação de transformação (permanentemente em curso, evidentemente) que afeta duas tradições - a indígena/diferenciante e o Estado brasileiro/convencionalizante. A profundidade desse deixar-se afetar é diferente num e noutro lado. Sobretudo devido aos modos distintos de se relacionar com o exterior e de lidar/ incorporar alteridades desses dois mundos. Enquanto de um lado - o indígena -, a incorporação de alteridades faz parte do modo de produzir-se a si mesmo, de outro - o estatal -, tende a "unificar" e diminuir contrastes e diferenças. Assim, se os índios "criam" e "inventam" a si mesmos e tentam "inventar" uma prefeitura indígena ao se relacionar com o Estado (não indígena), seja fora ou dentro dele; o Estado "cria" e "inventa" a si mesmo não apenas estatizando o índio, mas obliterando-o naquilo que é talvez a característica mais marcante desses povos, que é a multiplicidade.

Nesse sentido, argumento que o "insucesso" de uma "gestão indígena" na prefeitura de São Gabriel da Cachoeira é antes incapacidade do Estado do que incapacidade indígena. Ao contrário, os índios continuam, por diferentes meios, tentando "ocupar" e indigenizar o Estado. Essa é uma das vias ou batalhas na versão atualizada da guerra indígena contra (mas também com) o Estado. Entretanto, o que temos visto é que, em determinados aspectos, o Estado tem sido mais forte nessa disputa, cometendo genocídios, obstruindo e retirando direitos 
há algum tempo conquistados. Em outros aspectos, como no (re)conhecimento de seu inimigo, parece que os indígenas têm se saído melhor. Pode soar ingênuo afirmar que o Estado se enfraquece ou não se fortalece a partir do momento em que dois indígenas ocupam a prefeitura de um município tão periférico (do ponto de vista do Estado brasileiro), quando o que se vê no cenário nacional são os índios continuamente sendo dizimados. A insistência indígena em "ocupar" o Estado evidencia, porém, que efeitos estão sendo produzidos na vida deles. De outro modo, o que estou afirmando é que, na guerra indígena contra o Estado produz-se transformações tanto em si próprios quanto nos inimigos, pois trata-se sempre de uma relação na qual os indígenas incorporam elementos da alteridade estatal mas, na contrapartida, o Estado não incorpora elementos indígenas.

\section{CONTRA-O-ESTADO/COM-O-ESTADO: NOVAS CONFIGURAÇÕES DA GUERRA E DA POLÍTICA INDÍ́GENA VERSUS ESTATAL}

O caso etnográfico aqui visto amplia e sugere uma atualização da noção clastreana de contra-o-Estado. ${ }^{18}$ Nos dias atuais não se trata somente de recusar o Estado e a divisão/unificação promovida por ele, pois este não tem apenas uma existência potencial ou metafísica, é um ente atual, material e que tem produzido efeitos ambíguos na vida indígena - de um lado é genocida e atroz, de outro é promotor de direitos e de alguns serviços ou benefícios. Fato é que o Estado se tornou, a certa altura, um problema inescapável. Se a partir de dentro ou de fora, chegou-se num ponto que a única alternativa era com, ao mesmo tempo que contra, o que já aponta para uma das conclusões deste artigo. São várias as recusas do um, por assim dizer: recusa-se a unificação estatal, mas também se recusa um modo único de se relacionar com o Estado, no sentido de que se ambiciona poder ser com e contra simultaneamente, intenta-se até mesmo sero próprio Estado. ${ }^{19}$

É o que sugere André Baniwa ao evocar a possibilidade de ser ao mesmo tempo liderança indígena e vice-prefeito. A partir do exemplo Guarani, Clastres afirma a aversão ameríndia a tudo que se assemelhe ao um, e a busca incessante pela terra sem mal, onde o número ideal seria o dois, onde todos podem ser ao mesmo tempo homens e deuses, recusando a fronteira entre humanidade e divindade, conforme lembra Sztutman (2013). Isso porque o dois aqui em questão não é um simples par de unidades, mas o signo de uma diferença ou de uma transformação - pode-se ser homem e deus, pode-se passar de um a outro sem que a passagem aniquile um dos termos. É isso que está colocado por Andrée pelas avaliações indígenas da "gestão indígena": a recusa da aniquilação de um termo - o indígena - na política estatal; a recusa da ideia de que necessariamen-
18 O que também já foi apontado por Renato Sztutman (2013).

19 É preciso ainda refletir a questão do ponto de vista do Estado, no qual quase sempre ou de modo mais forte a perspectiva é contrao-indigena. Evidentemente o contra aqui tem outro sentido e outra potência, que poderia ser também explorado. Mas, é possível aventar, a partir do que foi exposto aqui, que este contra tem múltiplas possibilidades dependendo da relação e da posição que ambos - Estado e índios-ocupam. Quando estes estão "fora" do Estado, este é contra de um modo a tentar deixá-los a uma distância segura, por assim dizer, ou até mesmo exterminálos. Quando os índios estão dentro, o movimento contra do Estado se diversifica e tem de se reinventar, assim como os índios reinventam o contra-oEstado nesse momento. Embora, tenhamos visto, este dentro não é definitivo e as fronteiras entre dentro e fora são ambíguas e cambiáveis, ou ainda, o exterior é imanente ao interior. 
te deve-se deixar de ser liderança indígena para ser prefeito ou vice-prefeito. As acusações a Pedro foram, inclusive, no sentido de que ele teria sido "contaminado" (nos termos locais) ou capturado (nos termos antropológicos) pela política, pela lógica estatal, que ele teria cedido muito espaço para que brancos e "gente de fora" atuassem na prefeitura e, ainda, que ele teria feito alianças externas um tanto controversas.

Há ainda uma outra questão, um ponto diferenciante fundamental entre prefeito e liderança indígena. Se o um é mal, pois signo do finito, daquilo que nasce, cresce e se desenvolve somente para perecer (Clastres, 2003:190), "um prefeito" é diferente de "uma liderança", como aponta André em seu artigo sobre lideranças, no sentido de que um prefeito deixa de sê-lo, necessariamente, ao final de seu mandato, ao passo que uma liderança indígena não deixa essa posição jamais. Mas haveria aqui uma outra questão: Tânia Stolze Lima escreve:

Em estudos dedicados ao que chamou de metafísica guarani, Pierre Clastres ressal tou que não é porque o pensamento guarani recusa o um que devemos concluir sua opção pelo múltiplo - esta oposição sendo demasiadamente grega. Nem o um nem o múltiplo, trata-se antes de uma afirmação do dois. A verdade na cosmologia juruna (onde, aliás, inúmeros paralelos podem ser traçados com a cosmologia guarani), sendo decididamente al heia ao um, al heia ao ponto de vista de Sírio, foi por mim interpretada como pluralidade e polivocidade - projetada, como ela é, sobre planos cósmicos diferenciados ou dispersa entre pontos de vista diferentes. (1996: 34)

A questão seria referente ao problema que se desenhou, em nosso caso etnográfico, na polaridade dual entre prefeito e vice-prefeito. Parece que não é toda e qualquer composição dual que funcionaria do ponto de vista indígena. Ou tratar-se-ia de um caso específico, de um acirramento decorrente de outras polaridades (étnicas, políticas, partidárias, mitológicas, etc)?

De outro lado, o número que funciona no mundo indígena, o múltiplo, é impossível no mundo estatal. Estaríamos assim diante de um curto circuito com o qual os índios ainda terão que lidar para aprofundar a incorporação e a transformação do Estado. A experiência indígena na política estatal em São Gabriel da Cachoeira continua. Em 2016 foram eleitos novamente dois índios para os cargos de prefeito e vice-prefeito do município. No entanto, os discursos e as atitudes na campanha foram completamente diferentes daqueles que consagraram a vitória de Pedro e André em 2008. Desta vez, os candidatos vencedores não tiveram apoio do movimento indígena e parte de suas promessas de campanha eram referentes a uma suposta divisão de ganhos provenientes de projetos de mineração que viriam a ser desenvolvidos na cidade. Sabe-se que esta é 
uma questão que vai muito além da alçada de uma prefeitura. Mas fato é que a promessa convenceu uma parcela considerável dos eleitores. Resta ver como os índios efetuarão novas transformações internas e externas (neste exterior que também é interno, não esqueçamos).

Aline Fonseca lubel é pós-doutoranda do Departamento de Antropologia da Universidade Estadual de Campinas (Unicamp), doutora em Antropologia Social pela Universidade Federal de São Carlos (UFSCar) e mestre em Antropologia Social pela Universidade Federal do Paraná (UFPR).

\section{REFERÊNCIAS BIBLIOGRÁFICAS}

ADLER, Alfred

1980 "Fazedores de chuva, fazedores de ordem. Reflexão sobre as relações da magia e do poder na África Negra".

In Guerra, religião e poder. Lisboa, Edições 70.

ANDRELLO, Geraldo

2006 Cidade do índio: transformações e cotidiano em lauaretê. São

Paulo, Editora UNESP/ISA; Rio de Janeiro, NuTI.

BANIWA, André

2010 "O que é ser liderança segundo Mitologia, Ciência e Religião?" (texto cedido pelo autor).

BASSO, E.

1970 "Xingu Carib Kinship Terminology and Marriage: Another Review". Southwestern Journal of Anthropology, 26: 402-416.

1975 "Kalapalo Affinity: Its Cultural and Social Context". American Ethnologist, 2(2): 207-228.

CABALZAR, Aloísio

2009 Filhos da cobra de pedra: organização social e trajetórias tuyuka no rio Tiquié (noroeste amazônico). São Paulo, Editora da UNESP, ISA; Rio de Janeiro, NuTI. 
CHERNELA, Janet

1993 The Wanano Indians of the Brazilian Amazon. Austin, Texas University Press.

CLASTRES, Pierre

2003 A sociedade contra o Estado. São Paulo, Cosac e Naify.

2004 Arqueologia da violência-pesquisas de antropologia política. São Paulo, Cosac e Naify.

GARNELO, Luiza

2002 Poder, hierarquia e reciprocidade: os caminhos da política e da saúde no Alto Rio Negro. Campinas, tese de doutorado, Unicamp.

2004 "Tradição, modernidade e políticas públicas no alto Rio Negro". Somanlu (UFAM), Manaus, v. 4, n. 1: 29-53

\section{GAUCHET, Marcel}

1980 "A dívida do sentido e as razões do Estado. Política da religião primitiva". In Guerra, religião e poder. Lisboa, Ediçoes 70.

HUCH-JONES, Stephen

1988 "The Gun and the Bow. Myths of White Men and Indians". L'Homme, Paris, v. 106-7: 138-155.

1992 “Yesterday's Luxuries, Tomorrow's Necessities: Business and Barter in Northwest Amazonia". In HUCH-JONES, S. e HUMPHREY, C. (orgs.). Barter, Exchange and Value. An Anthropological Approach. Cambridge, Cambridge University Press.

IUBEL, Aline

2015 Transformações políticas e indígenas: movimento e prefeitura no alto rio Negro. São Carlos, tese de doutorado, UFSCar.

\section{JACKSON, Jean}

1983 The Fish People. Linguistic Exogamy and Tukanoan Identity in Northwest Amazonia. Cambridge, Cambridge Universtity Press.

LASMAR, Cristiane

2005 De volta ao lago de leite: gênero e transformações no Alto Rio Negro. São Paulo, Editora da UNESP, ISA; Rio de Janeiro, NuTI. 
LEIRNER, Piero

2015 "Diástole, sístole e a geopolítica do parentesco tukano". Paper apresentado na XI Reunión de Antropología del MERCOSUR (GT: O Parentesco Repensado), Montevideo, Uruguay, UNac.

LIMA, Tânia Stolze

1996 "O dois e seu múltiplo: reflexões em uma cosmologia tupi". Mana, 2(2): 21-47.

LUCIANO, Gersem José dos Santos

2006 "Projeto é como branco trabalha; as lideranças que se virem para aprender e nos ensinar": experiências dos povos indígenas do alto rio Negro. Brasília, dissertação de mestrado, UnB.

MAYBURY-LEWIS, David

1967 Akwe-Shavante Society. Oxford, Clarendon.

MENGET, Patrick

1993 "Les Frontières de la chefferie: remarques sur le système politique du Haut Xingu (Brésil)". L'Homme, 126-128 (2-4): 59-76.

NASCIMENTO, Luis Augusto

2017 Patrões, fregueses e donos: economia e xamanismo no Médio Rio Negro. São Carlos, tese de doutorado, UFSCar.

OVERING KAPLAN, Joanna

1972 "Cognation, Endogamy, and Technonimy: The Piaroa Example". Southwestern Journal of Anthropology, 28: 282-297.

1973 "Endogamy and the Marriage Alliance: A Note on the Continuity in Kindred-Based Croups". Man, 8(4): 555-570.

1975 The Piaroa, a People of the Orinoco Basin: A Study in Kinship and Marriage. Oxford, Clarendon.

1981 "Review Article, Amazonian Anthropology". Journal of Latin American Studies, n. 13: 151-164.

1983 "Elementary Structures of Reciprocity: A Comparative Note on Guianese, Central Brazilian, and the North-West Amazon Socio-Political Thought". Antropologica, v. 59-62: 331-348. 
PERES, Sidnei Clemente

2003 Cultura, política e identidade na Amazônia: o associativismo indígena no Baixo Rio Negro. Campinas, tese de doutorado, Unicamp.

PERRONE-MOISÉS, Beatriz

2011 "Bons chefes, maus chefes, chefões: elementos de

filosofia ameríndia". Revista de Antropologia, 54(2).

RIVIÈRE, P.

1969 Marriage Among the Trio: A Principle of Social

Organization. Oxford, Clarendon.

SOARES, Renato Martelli

2012 Das comunidades à federação: associações indígenas do Alto Rio Negro.

São Paulo, dissertação de mestrado, Universidade de São Paulo.

SZTUTMAN, Renato

2013 "Metamorfoses do contra-Estado: Pierre Clastres e as políticas ameríndias". Ponto Urbe, n. 13.

VIVEIROS DE CASTRO, Eduardo

1993 "Alguns aspectos da afinidade no dravidianato amazônico". In VIVEIROS DE CASTRO, E.; CARNEIRO DA CUNHA, M. (orgs.).

Amazônia: etnologia e história indígena. São Paulo, Núcleo de História Indígena e do Indigenismo-USP/Fapesp.

WAGNER, Roy

(1975) 2010 A invenção da cultura. São Paulo, Cosac e Naify. 


\section{ABSTRACT}

Based on some ethnographic considerations about the ethos of valorization and incorporation of otherness in Upper Rio Negro, this article reflects on the assessment made by the Indians themselves of the "indigenous administration" of the Town Hall of São Gabriel da Cachoeira (Amazonas State, Brazil). The argument is that since the Town Hall is an element that imposes relations exterior to the indigenous world, the attempt to indigenize it would require at least two procedures: the incorporation of relations and "elements of otherness"; and the incorporation of Indians in the Town Hall. According to some of those involved in this experience, the administration "wasn't indigenous" due to the excess of "people from the outside" and a certain "contamination" of the mayor by the "politics of the whites". However, an inescapable question is: to what degree could the state itself support dynamics that bring the simultaneity of differences intrinsic to the relations between Indians in the region? The analysis suggests that instead of a supposed incapacity of the Indians for state administration, there is the inability of the state to deal with and/or incorporate differences and alterities.

Recebido em 6 de abril de 2017. Aceito em 19 de outubro de 2017.

\section{KEYWORDS}

Indigenous

Prefecture,

Amerindian

Politics, Otherness,

Upper Rio Negro 